\title{
Knowledge Awareness and Practice Towards Management of Space Infections Among Dental Students
}

\author{
Ahmed Hilal Sheriff K ${ }^{1}$, Dhanraj Ganapathy ${ }^{2}$ and Subashree $\mathrm{R}^{3}$ \\ ${ }^{1}$ ASaveetha Dental College and Hospitals Saveetha Institute \\ of Medical and Technical Sciences Chennai, India \\ ${ }^{2}$ PProfessor and Head of the department Department of Prosthodontics Saveetha Dental College \\ and Hospitals, Saveetha Institute of Medical and Technical Sciences Chennai, India \\ ${ }^{3}$ Senior Lecturer Department of Prosthodontics Saveetha Dental College and Hospitals, \\ Saveetha Institute of Medical and Technical Sciences Chennai, India
}

\section{ABSTRACT}

The clinical presentation of odontogenic differs from each, depending on whether it is anterior vs posterior, maxilla vs mandible or if the infection is localized or disseminated. Like all infections, the clinical signs and symptoms are pain/ tenderness, redness, and swelling. Patients with superficial dental infections present with localized pain, cellulitis, and sensitivity to tooth percussion and temperature. However, patients with deep infections or abscesses that spread along the fascial planes may present with swelling; fever; and sometimes difficulty swallowing, opening the mouth, or breathing. A questionnaire consisting of 10 questions were prepared and distributed to 100 dental practitioners. The questionnaire consisted of questions about basic knowledge on odontogenic space infections and awareness regarding its management. The data was tabulated using microsoft excel and was imported into SPSS software for statistical analysis. This survey shows that most of the students had good knowledge and awareness regarding management of space infections. Figure 1 shows $72 \%$ of the dental students were aware that streptococcus viridans were the most common microorganism to cause odontogenic infections. From figure 2 it's seen that most of the students had excellent knowledge about space infections, prescription of antibiotics and signs and symptoms of odontogenic infections. Most of the students (59\% and 63\%) commonly practiced eradicating the source of infection primarily without delaying it by giving antibiotics or incision drainage as seen in figure 3. From figure 4 and figure 5, 57\% of the students prescribed amoxicillin and 53\% of the students prescribed clindamycin for penicillin allergic patients as their first choice of drug incase of odontogenic infections. Within the limit of the study, it can be concluded that the dental students were well aware of the space infections and management of odontogenic space infections. Although, this study was done in a small sample size and further studies with large sample size would be better to generalise the results of this study

\section{KEY WORDS: ABSCESS; AMOXICILLIN; CLINDAMYCIN; INCISION DRAINAGE; STREPTOCOCCUS VIRIDANS.}

\section{ARTICLE INFORMATION}

*Corresponding Author: dhanraj@saveetha.com

Received 15th June 2020 Accepted after revision 5th August 2020

Print ISSN: 0974-6455 Online ISSN: 2321-4007 CODEN: BBRCBA

Thomson Reuters ISI Web of Science Clarivate Analytics USA and Crossref Indexed Journal

$$
\begin{aligned}
& \text { Clarivate } \\
& \text { Analytics }
\end{aligned}
$$




\section{INTRODUCTION}

An odontogenic infection is an infection of the alveolus, jaws, or face that arises from a tooth or it's supporting structures and is one of the most frequently occurring infections. The most common causes of odontogenic infections are dental caries, deep fillings or failed root canal treatment, pericoronitis, and periodontal disease. The infections are usually localized around a tooth and may remain localized to the section where it started, or may spread into adjacent or distant areas. The course of the infection depends on the virulence of the bacteria, host resistance factors, and the regional anatomy.

The clinical presentation of odontogenic differs from each, depending on whether it is anterior vs posterior, maxilla vs mandible or if the infection is localized or disseminated. Like all infections, the clinical signs and symptoms are pain/tenderness, redness, and swelling. Patients with superficial dental infections present with localized pain, cellulitis, and sensitivity to tooth percussion and temperature(Holmes and Pellecchia, 2016). However, patients with deep infections or abscesses that spread along the fascial planes may present with swelling; fever; and sometimes difficulty swallowing, opening the mouth, or breathing(Santosh, Viresh and Sharmada, 2014).

In the dental clinic, there are a number of conditions that can be considered as unscheduled dental emergencies like tooth pain, to a fractured or avulsed tooth, to odontogenic infections. For the dentist management of odontogenic infections can be the most concerning of these emergencies owing to its complex microbiology and potential for advancement to life threatening medical emergencies. Odontogenic infections encompass a variety of conditions ranging from localized abscesses to deep space head and neck infections(Lypka and Hammoudeh, 2011). Deep space infections can carry a high incidence of morbidity and mortality(Sato et al., 2009). It is imperative for the dental professional to have an understanding of treatment and management of such infections. Management of patients with an odontogenic infection is a comprehensive approach involving an examination and evaluation of the patient, identifying source of the infection, anatomic considerations, surgical intervention, and appropriate antimicrobial therapy.

Previously our department has conducted extensive research on various aspects of prosthetic dentistry, like in vitro studies, surveys, clinical trials and review(Ashok et al., 2014; Venugopalan et al., 2014; Ashok and Suvitha, 2016; Ganapathy et al., 2016; Selvan and Ganapathy, 2016; Subasree, Murthykumar and Others, 2016; Vijayalakshmi and Ganapathy, 2016; Ajay et al., 2017; Ganapathy, Kannan and Venugopalan, 2017; Jyothi, Robin and Ganapathy, 2017; Ranganathan, Ganapathy and Jain, 2017; Basha, Ganapathy and Venugopalan, 2018; Jain et al., 2018; Kannan and Venugopalan, 2018; Duraisamy et al., 2019). This study was conducted to assess the knowledge aware and practice towards the management of space infections among the dental students.

\section{MATERIAL AND METHODS}

A questionnaire consisting of 10 questions were prepared and distributed to 100 dental students to assess their knowledge, awareness and practice towards management of space infections among dental students. The questionnaire was prepared online using a survey planet and the link was distributed to the dental practitioners to fill the survey. The questionnaire contained questions about basic knowledge on odontogenic space infections and awareness regarding its management. The data was tabulated using microsoft excel and was imported into SPSS software for statistical analysis.

\section{Questionnaire}

1. What are the most common microorganisms in odontogenic infection?

2. Are you aware of Management of space infections?

3. Most common cause of space infection is Dental Caries / Periodontal Infections?

4. Signs of severe odontogenic infection include facial or neck swelling and tenderness, dysphagia, dyspnea, trismus

5. Would you prescribe antibiotics after a routine surgical extraction?

6. Do you think routine prescription of antibiotics when not needed increases resistance of bacteria?

7. What is your immediate management of a patient with a canine space infection, which is hard, causing swelling of the cheek and extending to the eye?

8. Management of submandibular space infection associated with fever and dehydration?

9. First choice of antibiotic for Odontogenic infections?

10. First choice of antibiotic for Odontogenic infections in the penicillin allergic patients?

\section{RESULTS AND DISCUSSION}

This survey shows that most of the students had good knowledge and awareness regarding management of space infections. Figure 1 shows $72 \%$ of the dental students were aware that streptococcus viridans were the most common microorganism to cause odontogenic infections. From figure 2 it's seen that most of the students had excellent knowledge about space infections, prescription of antibiotics and signs and symptoms of odontogenic infections. Most of the students (59\% and 63\%) commonly practiced eradicating the source of infection primarily without delaying it by giving antibiotics or incision drainage as seen in figure 3. From figure 4 and figure 5, 57\% of the students prescribed amoxicillin and 53\% of the students prescribed clindamycin for penicillin allergic patients as their first choice of drug incase of odontogenic infections.

The pyogenic oro-fascial infections are most commonly odontogenic in origin like periapical abscesses to 
superficial and deep infections in the neck. If left untreated, they generally spread into the adjacent fascial spaces like masseteric, sublingual, submandibular, temporal, buccal, canine and parapharyngeal and which may lead to additional complications. Early recognition of infections and appropriate therapy is essential(Bahl et al., 2014). Most dental abscesses are caused by the host oral microflora that enters normally sterile tissues. The major isolates are streptococci and anaerobic bacteria, which are regarded as normal flora of the tooth and gingival crevice(Hardie and Bowden, 1974). In this survey the $72 \%$ of the students consented to this stating that Streptococcus viridans were major causative organisms for odontogenic infections as seen in figure 1.

Figure 1: Bar graph showing the awareness among the students regarding common microorganism in odontogenic infection. $\mathrm{X}$ axis represents commonest microorganisms and $\mathrm{Y}$ axis represents number of dental students. From this graph we can infer that most of the dental students(72\%) were aware that streptococcus viridans(blue) was the most common microorganism causing odontogenic infection.

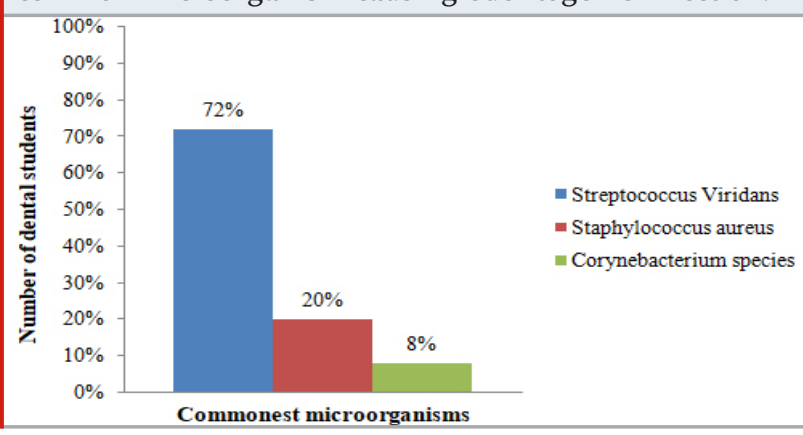

Figure 2: Bar graph showing series of questions regarding awareness of space infections among dental students. $\mathrm{X}$ axis represents close ended questions and y axis represents number of dental students. Blue denotes yes and red denotes no. From this graph we can infer that most of the students were having good knowledge about space infections.

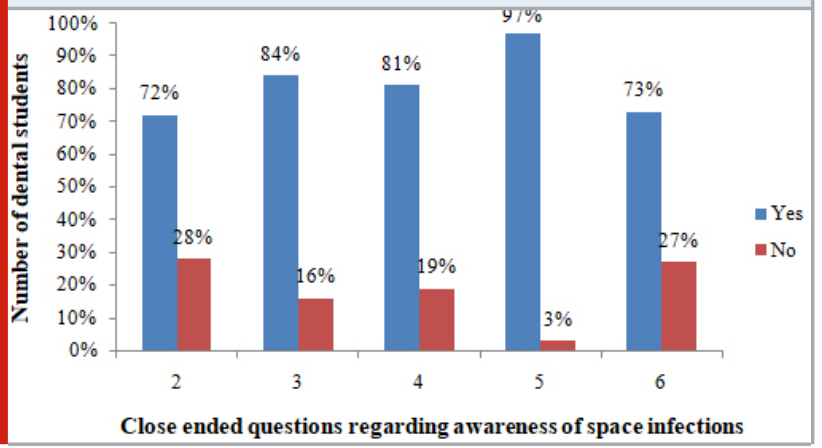

From figure 2, the dental students reported that they were well aware (84\%) of the causes of Odontogenic space which was by bacterial infections arising from pre-existing dental caries-such as pulpitis and apical periodontitis, pericoronitis or periodontal diseases. Other documented causes include tonsillitis, gunshot injuries, peritonsillar or parapharyngeal abscesses, mandibular fracture, oral lacerations/piercings, or submandibular sialadenitis. Predisposing factors include recent dental treatment, systemic illnesses such as diabetes mellitus, malnutrition, alcoholism, compromised immune system such as acquired-immunodeficiency syndrome (AIDS), and organ transplantation(Kurien et al., 1997; Osunde et al., 2012). Clinical presentation of this infection may arise from toothache to limitation of mouth opening, fever, malaise, dysphagia. In their most severe form, space infections can lead to death, which usually results from an acute airway obstruction or multiorgan failure(Kurien et al., 1997).

The signs and symptoms presented by patients with severe infection due to odontogenic origin are crucial factors. Sato et al., has shown in their eight-year retrospective study that odontogenic infection cases require immediate attention either clinical or surgical therapy. The most frequent signs and symptoms found are trismus, fever, dysphagia, pain and swelling(Flynn et al., 2006; Sato et al., 2009). The patient's medical history and current medications help in assessing the patient's ability to fight infection as well as providing insight to potential drug interactions. From this survey it is seen that the dental students (81\%) were well aware regarding the signs and symptoms of space infection as seen in figure 2 . While we discuss the signs and symptoms, it is important for us to look into "Ludwig's Angina" as they are the most dangerous type of space infection as it is a lifethreatening infection. It has 'brawny boardlike swelling' of the submandibular, sublingual and the submental region with edema and elevation of tongue leading to drooling which also causes airway obstruction(Patterson, Kelly and Strome, 1982; Kim et al., 2012). The most common cause of death in case of ludwig's angina is due to airway obstruction as it is the most life threatening complication(Candamourty et al., 2012).

The judgment on how to approach an odontogenic infection is based on the source of the infection, severity of the infection, and state of the patient's host defense mechanisms. The first and most important element in treating dental infections is the elimination of the primary source of the infection. In the case of an acute abscess, incision and drainage to remove accumulated pus (purulence) that contains bacteria is required. The incision and drainage procedure must break all the loculi within the abscess cavity and evacuate as much of the pus as possible. Following the evacuation of the purulent exudate, the use of irrigation further dilutes the bacterial population. While discussing management of these odontogenic infections this survey shows that $72 \%$ of the dental students are aware of management of space infections as seen in figure 2 .

As a painkiller and as well as to eradicate the infection we prescribe patients with NSAIDs and antibiotics routinely after a surgical extraction and this was also followed by the $97 \%$ of the dental students as seen in figure 2 . This can be followed for cases that do not include the deep spaces or abscesses, but when it comes to space 
infections, the dentist must be well aware of the approach of the treatment of these infections. Penicillin is the drug of choice in treating space infections because it is effective against the gram-positive aerobes and intraoral anaerobes commonly found in alveolar abscesses. Both aerobic and anaerobic microorganisms are susceptible to penicillin(Sabiston and Gold, 1974). The first drug of choice in the management of odontogenic infection is Amoxicillin, which is a semi-synthetic antibiotic belonging to the penicillin group of drugs. It has broad spectrum bactericidal activity against gram-positive and gram-negative organisms.

Figure 3: Bar graph showing the awareness among the dental students regarding clinical management of space infection. $\mathrm{X}$ axis represents clinical management and $\mathrm{Y}$ axis represents the number of dental students. From this graph we can infer that 59\% and $63 \%$ of the students commonly opted to remove the source of infection(Green) first without delaying it with antibiotics/ ICtD.

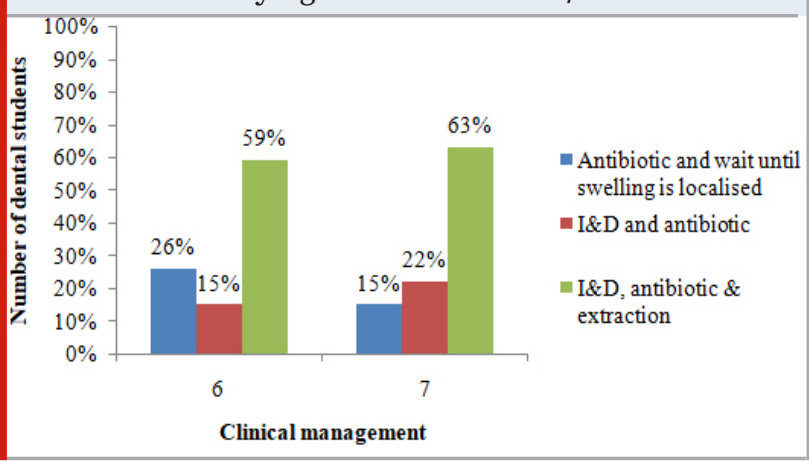

Figure 4: Bar graph showing awareness among the students regarding the first choice of antibiotics incase of odontogenic infections. $\mathrm{X}$ axis represents Choice of antibiotics and $\mathrm{Y}$ axis represents number of dental students. From this graph we can infer that $57 \%$ of the students prescribed amoxicillin(Blue) as their first choice of drug incase of odontogenic infections.

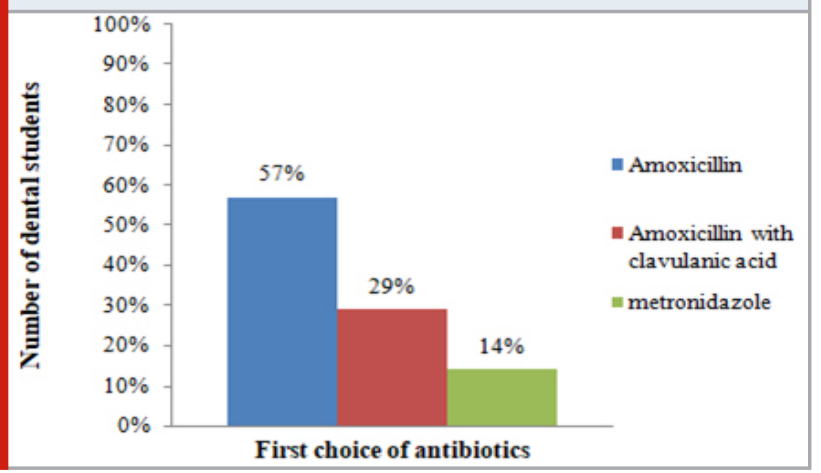

A study done by Raquel González-Martínez et al., shows that amoxicillin is the first choice of drug prescribed by the dentists(González-Martínez et al., 2012), this coincides with our survey stating that $57 \%$ of the dental students also practice the same, whereas the drug of choice for penicillin allergic patients, 53\% of the dental students were aware clindamycin to be the first choice of drug as seen in figure 4 \& 5 . In a study conducted by Bascones et al. and Isla et al., they performed pharmacokinetic and pharmacodynamic analysis and concluded that amoxicillin in combination with clavulanic acid, and clindamycin are adequately effective against microorganisms isolated from odontogenic infections, while spiramycin and metronidazole do not cover the bacterial spectrum bacterial of this type of infections(Bascones Martínez et al., 2004; Isla et al., 2005).

Though, most respondents (73\%)(figure 2) believed that prescribing antibiotics unnecessarily increases resistance in the community, a significant number of students still prescribe antibiotics in situations when it is not necessarily indicated. This could be attributed to the student's efforts to prevent infection. However, removal of the potential source of infection is always sufficient as shown by previous studies(Bodner et al., 2012; Igoumenakis et al., 2015). This is a more global issue that has been reported in the United States, Nigeria, Czech Republic, and Japan, KSA(Masuda et al., 2012; Pipalova, Vlcek and Slezak, 2014; Akinyemi et al., 2015; Vandepitte, Ponthong and Srisarang, 2015; Al-Sebaei and Jan, 2016). Practitioners must be highly careful when prescribing amoxicillin/clavulanate, because there has already been some evidence of resistant strains of Escherichia coli and Salmonella spp. reported in several studies(Masuda et al., 2012; Akinyemi et al., 2015). In a study by Poeschl et al, the resistance rate in severe deep space head and neck infections was found to be $14 \%$ against clindamycin, 14\% against macrolides, and 7\% against Penicillin G(Poeschl et al., 2010).

Figure 5: Bar graph showing awareness among the students regarding the first choice of antibiotics incase of odontogenic infections in penicillin allergic patients. $\mathrm{X}$ axis represents Choice of antibiotics and $\mathrm{Y}$ axis represents number of dental students. From this graph we can infer that $53 \%$ of the students prescribed Clindamycin(Blue) as their first choice of drug incase of odontogenic infections among penicillin allergic patients.

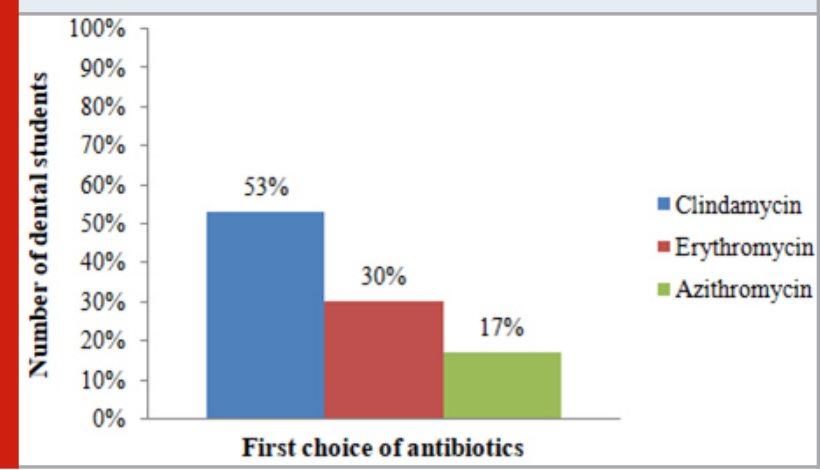

Open surgical incision and drainage are considered the mainstay of treatment for submandibular space abscesses and Ludwig's angina. It is better to treat all patients with large doses of broad-spectrum intravenous antibiotics (e.g., amoxicillin/clavulanate potassium) until culture 
results identify the causative organism. In cases of large abscesses or multiple space involvement, an open surgical incision and drainage are swiftly performed. In patients with small abscesses, a watch and wait policy is applied for 48 hours; if a lack of response to medical treatment is noted clinically, the patient is treated with an open surgical drainage. Among respondents, more than half of them (59\% and 63\%)(figure 3) suggested eliminating the source of infection that is extraction of the tooth, then IED and prescribe antibiotics in case of immediate management of the patient which was in contradiction to the study done by Maisa $\mathrm{O}$. Al-Sebaei et al.,[23] in which their respondents had a general tendency to delay the surgical approach by prescribing antibiotics and wait for the swelling to localize.

\section{CONCLUSION}

Within the limit of the study, it can be concluded that most of the dental students were well aware of the space infections and management of odontogenic space infections. Although, this study was done in a small sample size and further studies with large sample size would be better to generalise the results of this study.

\section{ACKNOWLEDGEMENTS}

The authors would like to acknowledge the help and support rendered by the Department of Prosthodontics and Department of Information Technology of Saveetha Dental College and Hospitals, SIMATS for their constant assistance for this research.

\section{Conflict of Interest: Nil}

\section{REFERENCES}

Ajay, R. et al. (2017) 'Effect of surface modifications on the retention of cement-retained implant crowns under fatigue loads: An In vitro study', Journal of Pharmacy And Bioallied Sciences, p. 154. doi: 10.4103/ jpbs.jpbs_146_17.

Akinyemi, K. O. et al. (2015) ‘bla CTX-M-I group extended spectrum beta lactamase-producing Salmonella typhi from hospitalized patients in Lagos, Nigeria', Infection and drug resistance. ncbi.nlm.nih.gov, 8, pp. 99-106. Al-Sebaei, M. 0. and Jan, A. M. (2016) 'A survey to assess knowledge, practice, and attitude of dentists in the Western region of Saudi Arabia', Saudi medical journal. ncbi.nlm.nih.gov, 37(4), pp. 440-445.

Ashok, V. et al. (2014) 'Lip Bumper Prosthesis for an Acromegaly Patient: A Clinical Report', Journal of Indian Prosthodontic Society, 14(Suppl 1), pp. 279282.

Ashok, V. and Suvitha, S. (2016) 'Awareness of all ceramic restoration in rural population', Journal of pharmacy research. indianjournals.com. Available at: http://www.indianjournals.com/ijor.aspx?target=ijor:rj ptCtvolume $=9$ \&tissue $=10 \&$ tarticle $=039$ ttype $=$ pdf.

Bahl, R. et al. (2014) 'Odontogenic infections: Microbiology and management', Contemporary clinical dentistry. ncbi.nlm.nih.gov, 5(3), pp. 307-311.

Bascones Martínez, A. et al. (2004) 'Consensus statement on antimicrobial treatment of odontogenic bacterial infections', Medicina oral, patologia oral y cirugia bucal. SciELO Espana, 9(5), pp. 369-76; 363-9.

Basha, F. Y. S., Ganapathy, D. and Venugopalan, S. (2018) 'Oral Hygiene Status among Pregnant Women', Research Journal of Pharmacy and Technology. A \& V Publications, 11(7), pp. 3099-3102.

Bodner, L. et al. (2012) 'Cutaneous Sinus Tract of Dental Origin in Children-A Report of 28 New Cases', Pediatric dermatology. Wiley Online Library, 29(4), pp. 421-425.

Candamourty, R. et al. (2012) 'Ludwig's Angina - An emergency: A case report with literature review', Journal of natural science, biology, and medicine. ncbi.nlm.nih. gov, 3(2), pp. 206-208.

Duraisamy, R. et al. (2019) ‘Compatibility of Nonoriginal Abutments With Implants: Evaluation of Microgap at the Implant-Abutment Interface, With Original and Nonoriginal Abutments', Implant dentistry, 28(3), pp. 289-295.

Flynn, T. R. et al. (2006) 'Severe odontogenic infections, part 1: prospective report', Journal of oral and maxillofacial surgery: official journal of the American Association of Oral and Maxillofacial Surgeons. Elsevier, 64(7), pp. 1093-1103.

Ganapathy, D. et al. (2016) 'Effect of Resin Bonded Luting Agents Influencing Marginal Discrepancy in All Ceramic Complete Veneer Crowns', Journal of clinical and diagnostic research: JCDR, 10(12), pp. ZC67-ZC70.

Ganapathy, D. M., Kannan, A. and Venugopalan, S. (2017) 'Effect of Coated Surfaces influencing Screw Loosening in Implants: A Systematic Review and Metaanalysis', World Journal of Dentistry, pp. 496-502. doi: 10.5005/jp-journals-10015-1493.

González-Martínez, R. et al. (2012) 'Antibiotic prescription in the treatment of odontogenic infection by health professionals: A factor to consensus', Medicina oral, patologia oral y cirugia bucal. Medicina Oral SL, 17(3), p. e452.

Hardie, J. M. and Bowden, G. H. (1974) 'The normal microbial flora of the mouth', Society for Applied Bacteriology symposium series. europepmc.org, 3(0), pp. 47-83.

Holmes, C. J. and Pellecchia, R. (2016) 'Antimicrobial Therapy in Management of Odontogenic Infections in General Dentistry', Dental clinics of North America. hsjd.cl, 60(2), pp. 497-507.

Igoumenakis, D. et al. (2015) 'Effect of Causative Tooth Extraction on Clinical and Biological Parameters of Odontogenic Infection: A Prospective Clinical Trial', Journal of oral and maxillofacial surgery: official journal of the American Association of Oral and Maxillofacial Surgeons. Elsevier, 73(7), pp. 1254-1258.

Isla, A. et al. (2005) 'Pharmacokinetic/pharmacodynamic 
evaluation of antimicrobial treatments of orofacial odontogenic infections', Clinical pharmacokinetics. Springer, 44(3), pp. 305-316.

Jain, A. R. et al. (2018) 'Determination of correlation of width of maxillary anterior teeth using extraoral and intraoral factors in Indian population: A systematic review', World J Dent. researchgate. net. Available at: https://www.researchgate.net/ profile/Ashish_Jain52/publication/323548671_ Determination_of_correlation_of_width_of_maxillary_ anterior_teeth_using_extraoral_and_intraoral_ factors_in_indian_population_A_systematic_review/ links/5b00347c0f7e9be94bd8caf9/Determination-ofcorrelation-of-width-of-maxillary-anterior-teethusing-extraoral-and-intraoral-factors-in-indianpopulation-A-systematic-review.pdf.

Jyothi, S., Robin, P. K. and Ganapathy, D. (2017) 'Periodontal health status of three different groups wearing temporary partial denture', Research Journal of. indianjournals.com. Available at: http://www. indianjournals.com/ijor.aspx?target=ijor:rjptttvolume $=10 \mathrm{Ctissue}=12 \mathrm{Etarticle}=046$.

Kannan, A. and Venugopalan, S. (2018) 'A systematic review on the effect of use of impregnated retraction cords on gingiva', Research Journal of Pharmacy and Technology. A \&t V Publications, 11(5), pp. 21212126.

Kim, M. K. et al. (2012) 'Burden of facial cellulitis: estimates from the Nationwide Emergency Department Sample', Oral surgery, oral medicine, oral pathology and oral radiology. Elsevier, 114(3), pp. 312-317.

Kurien, M. et al. (1997) 'Ludwig's angina', Clinical otolaryngology and allied sciences. Wiley Online Library, 22(3), pp. 263-265.

Lypka, M. and Hammoudeh, J. (2011) 'Dentoalveolar infections', Oral and maxillofacial surgery clinics of North America. oralmaxsurgery.theclinics.com, 23(3), pp. 415-424.

Masuda, K. et al. (2012) 'Amoxicillin-resistant oral streptococci identified in dental plaque specimens from healthy Japanese adults', Journal of cardiology. Elsevier, 59(3), pp. 285-290.

Osunde, 0. D. et al. (2012) 'Management of fascial space infections in a Nigerian teaching hospital: A 4-year review', Nigerian medical journal: journal of the Nigeria Medical Association. ncbi.nlm.nih.gov, 53(1), pp. 12-15.

Patterson, H. C., Kelly, J. H. and Strome, M. (1982) 'Ludwig's angina: an update', The Laryngoscope. Wiley Online Library, 92(4), pp. 370-378.

Pipalova, R., Vlcek, J. and Slezak, R. (2014) 'The trends in antibiotic use by general dental practitioners in the C zech R epublic (2006--2012)', International dental journal. Wiley Online Library, 64(3), pp. 138-143.

Poeschl, P. W. et al. (2010) 'Antibiotic susceptibility and resistance of the odontogenic microbiological spectrum and its clinical impact on severe deep space head and neck infections', Oral surgery, oral medicine, oral pathology, oral radiology, and endodontics. Elsevier, 110(2), pp. 151-156.

Ranganathan, H., Ganapathy, D. M. and Jain, A. R. (2017) 'Cervical and Incisal Marginal Discrepancy in Ceramic Laminate Veneering Materials: A SEM Analysis', Contemporary clinical dentistry, 8(2), pp. 272-278.

Sabiston, C. B., Jr and Gold, W. A. (1974) 'Anaerobic bacteria in oral infections', Oral surgery, oral medicine, and oral pathology. Elsevier, 38(2), pp. 187-192.

Santosh, A. N., Viresh, A. N. and Sharmada, B. K. (2014) 'Microbiology and antibiotic sensitivity of odontogenic space infection', International journal of Medical and Dental Sciences, 3(1), pp. 303-313.

Sato, F. R. L. et al. (2009) 'Eight-year retrospective study of odontogenic origin infections in a postgraduation program on oral and maxillofacial surgery', Journal of oral and maxillofacial surgery: official journal of the American Association of Oral and Maxillofacial Surgeons. Elsevier, 67(5), pp. 1092-1097.

Selvan, S. R. and Ganapathy, D. (2016) 'Efficacy of fifth generation cephalosporins against methicillin-resistant Staphylococcus aureus-A review', Research Journal of Pharmacy and Technology. A \& V Publications, 9(10), pp. 1815-1818.

Subasree, S., Murthykumar, K. and Others (2016) 'Effect of Aloe Vera in Oral Health-A Review', Research Journal of Pharmacy and Technology. A \& V Publications, 9(5), pp. 609-612.

Vandepitte, W. P., Ponthong, R. and Srisarang, S. (2015) 'Treatment Outcomes of the Uncomplicated Upper Respiratory Tract Infection and Acute Diarrhea in Preschool Children Comparing Those with and without Antibiotic Prescription', Journal of the Medical Association of Thailand $=$ Chotmaihet thangphaet. thaiscience.info, 98(10), pp. 974-984.

Venugopalan, S. et al. (2014) 'Case Report: Magnetically retained silicone facial prosthesis', Nigerian journal of clinical practice. ajol.info, 17(2), pp. 260-264.

Vijayalakshmi, B. and Ganapathy, D. (2016) 'Medical management of cellulitis', Research Journal of Pharmacy and Technology. A \& V Publications, 9(11), pp. 2067-2070. 